\title{
Luteolin isolate from the methanol extract identified as the single- carbon compound responsible for broad antiulcer activities of Cassia singueana Leaves.
}

\author{
O.J. Ode ${ }^{1 *}$, I.U. Asuzu ${ }^{2}$ \\ ${ }^{1}$ Department of Veterinary Pharmacology \& Toxicology, University of Abuja, P.M.B. 117, Abuja, Nigeria. \\ ${ }^{2}$ Prof. I. U. Asuzu, Department of Veterinary Physiology \& Pharmacology, University of Nigeria, Nsukka, \\ Nigeria.
}

\begin{abstract}
The results of earlier studies by my team of researchers demonstrated the wide spectrum of in vivo gastro-protective effects of the methanol extract of Cassia singueana leaves (MECSL) in rats. The crude extract exhibited profound potency against experimentally-induced ulcerative lesions in various gastric ulcer induction models (pyloric ligation/histamine, indomethacin and ethanol-mediated stomach ulcers) in rats. The activities of the extract thus, authenticated the claim of high folkloric efficacy of the plant leaves in diverse chronic peptic ulcer therapies in Northern Nigeria. Bioassay-guided fraction using column chromatography, thin layer chromatography (TLC) and indomethacin treatment afforded the isolation of the bioactive compound. A further TLC purification of this pure compound facilitated the isolation of the single-carbon antiulcer agent from MECSL. Structural and molecular elucidation of this active principle with Nuclear magnetic resonance $(N M R)$ spectroscopy and mass spectrometry enabled its identification as luteolin. Luteolin is a known compound which is safe and possesses multiplicity of effects against gastric ulceration. The results of this study provide indications for conducting clinical trials with luteolin as a potential sole antiulcer agent.
\end{abstract}

KEYWORDS: Antiulcer; Cassia singueana; Helicobacter pylori; Luteolin; Indomethacin

\section{INTRODUCTION}

Peptic ulcer affects an appreciable number of people globally and despite advances in medicine, treatment remains a challenge. The disease is a common cause of burning sensation, pains and gnawing arising from the gastro-intestinal tract. Multiple factors including prolonged starvation, disruption of gastric mucosal barrier by stress [1], decrease in alkaline mucosal bicarbonate and mucus secretion, over dosage and/or prolonged administration of non-steroidal anti-inflammatory drugs [2], persistent infection with Helicobacter pylori, the damaging effects of reactive oxygen species [3] and genetic factors are implicated in the aetiology of the disease. However, the pathophysiology of gastric ulceration is simply due to an imbalance between aggressive factors (hydrochloric acid, pepsin, H. pylori and non-steroidal anti-inflammatory agents) and local mucosal defensive factors (mucus bicarbonate, increased blood flow and prostaglandins). Stomach ulcer results from the over-bearing effects of the aggressive factors; histamine is considered as a critical regulator of gastric acid secretion [4].

In the treatment of peptic ulcer, various drug combinations involving histamine $\mathrm{H}_{2^{-}}$- receptor antagonists, analgesics, broadspectrum antibiotics, proton pump inhibitors, antacids and gastric mucosal protectants are often administered. The antiulcer drugs require prolonged periods to be taken (4-8 weeks) for successful therapy, yet ulcer relapse is a common occurrence after cessation of treatment [5]. The management is also complicated by numerous adverse effects of the antiulcer drugs in the absence of a novel agent that proves solely effective [6]. It therefore becomes imperative to explore for a potent antiulcer agent to overcome the challenges in peptic ulcer treatment.Fortunately, concoctions from the leaves of $C$. singueana plant, a Leguminosae, were adjudged to offer reliable recipe in chronic cases of peptic ulcer among the Hausa and Fulani tribes of Northern Nigeria. The crude methanol extract of the leaves was found to be potent in reducing ulcer lesions from various in vivo gastric ulcer induction models (pyloric ligation/histamine, indomethacin and ethanol treatment) in rats $([7,8,9]$. The crude extract also demonstrated a high antioxidant activity of $66 \%$ compared to $79 \%$ with ascorbic acid, a standard antioxidant at $400 \mu \mathrm{g} / \mathrm{mL}$ using 1, 1-Diphenyl-2-picrylhydrazyl radical (DPPH) spectrophotometric assay [10]. The present study focused on isolation, purification and identification of the bioactive principle (s) against gastric ulceration in MECSL to facilitate evaluation of possible mechanism (s) of action in the observed wide spectrum antiulcer effects. 


\subsection{Experimental animals}

\section{MATERIALS AND METHODS}

Matured inbred albino rats of both sexes weighing between 90-200 g were obtained from the Laboratory Animal unit of the College of Health Sciences, Benue State University, Makurdi in Nigeria. Animals were kept in stainless steel cages and had access to feed (Vital feed®, Nigeria Ltd.) and water ad libitum. Animal room temperature and relative humidity were $28-30{ }^{\circ} \mathrm{C}$ and $30-70 \%$, respectively, and there was $12 \mathrm{~h}$ light/dark cycle daily. The rats were allowed 14 days to acclimatize prior to commencement of experiments. The use of the animals conformed with internationally accepted standards for laboratory animal use and care as documented in the European Community guidelines, Council Directive, 1986 (86/609/EEC) [11], revised in Directive 2010/63/EU [12]. The experimental protocols were approved by the Ethics Committee for Animal Experimentation, UNN, in accordance with Nigerian Federal Government legislation on Animal care.

\subsection{Reagents, chemicals and equipment}

Methanol, hexane, chloroform and ethylacetate were obtained from Sigma Aldrich, USA; concentrated tetraoxosulphate (IV) acid $\left(\mathrm{H}_{2} \mathrm{SO} 4\right)$ from BDH laboratories, England; vanillin, Whatman filter paper, scapel blade, magnifying lens, ultraviolet lamp (UV) (Yalien, China), $0.20 \mathrm{~mm}$ silica gel ( $\mathrm{GF}_{254}$ on polyester plate) from Merk Co, USA, silica gel $\mathrm{GF}_{254}$ (Kieselgel 60 G Merck), Glass column, TLC tank and glass plates ( $20 \mathrm{x} 20$ $\mathrm{cm}$ ) were used in the study. NMR data were obtained on a JEOL Eclipse (400 MHZ) and Bruker (600 MHZ).

\subsection{Plant collection and identification}

Fresh leaves of the plant were collected from Kumbotso Local Government Area within Kano metropolis, Northern Nigeria in September, 2013. The plant was duely identified as Cassia singueana by Mr. Ozioko Alfred, a taxonomist with Bioresources Development and Conservation programme (BDCP), Aku road, Nsukka, Enugu State, Nigeria.

\subsection{Preparation and extraction of the plant material}

Fresh $C$. singueana leaves were dried under mild sunlight, pulverized into coarse powder with mortar and pestle before grinding into fine particles in a laboratory hammer mill. Cold extraction of $600 \mathrm{~g}$ of the powdered material was performed for $48 \mathrm{~h}$ using $80 \%$ methanol with intermittent shaking at $2 \mathrm{~h}$ interval. The extract was concentrated in vacuo using a rotary evaporator at $40{ }^{\circ} \mathrm{C}$. The percentage yield of the extract was determined. The methanol extract of $C$. singueana leaves obtained was denoted as MECSL and maintained in a refrigerator at $4{ }^{\circ} \mathrm{C}$ until when used for studies.

\subsection{Column chromatography}

A given mass (5 g) of the extract (MECSL) was subjected to column chromatography to separate the extract into its component fractions. Silica gel $60 \mathrm{G}$ was used as the stationary phase while different solvent combinations of increasing polarity were used as the mobile phase [13]. The column was allowed $24 \mathrm{~h}$ to stabilize after the set-up. Elution of the extract was done sequentially with solvent systems of gradually increasing polarity using hexane, chloroform, ethylacetate and methanol in the following ratio: Hexane: chloroform 100:0, 80:20, 60:40, 40:60, and 20:80; Chloroform: ethylacetate 100:0, 80:20, 60:40, 40:60, and 20:80; Ethylacetate: methanol 100:0, 80:20, 60:40, 40:60, 20:80 and 0:100. A measured volume (400 ml) of each solvent combination was used in the elution process. The fractions were collected in aliquots of $10 \mathrm{ml}$ in test tubes. Collections were allowed two days to concentrate at room temperature $\left(37^{\circ} \mathrm{C}\right)$

The content of each test tube was spotted on pre-coated (silica gel F254) aluminium plates in a small chromatographic tank to separate the different fractions based on their relative mobilities in solvent systems and color reactions with ultra-violet light at 254 and $365 \mathrm{~nm}$ (analytical TLC performed). The content of test tubes with the same retention factor were pooled together and concentrated in a rotovaporator at $40{ }^{\circ} \mathrm{C}$.

\subsection{Bioassay screening of fractions with indomethacin-induced gastric ulceration}

Extract fractions 1 to 7 (F1-7) demonstrated no antiulcer activity in the preliminary investigation and were subsequently discarded. Fifteen rats were randomly allocated to 3 groups (I-III) with 5 rats per group. Animals were deprived of feed for $24 \mathrm{~h}$ prior to the experiment. Group I served as the negative control and was drenched with an equivalent volume $(10 \mathrm{ml} / \mathrm{kg}$ ) of the vehicle (distilled water). Group II was given an oral treatment of cimetidine $(100 \mathrm{mg} / \mathrm{kg})$ while group III was treated with fraction $8(\mathrm{~F} 8,100 \mu \mathrm{g} / \mathrm{kg})$ from the MECSL. After $30 \mathrm{~min}$, each rat was given an oral dose $(40 \mathrm{mg} / \mathrm{kg})$ of indomethacin to induce ulcerative lesions in the rat stomachs. All treatments were administered by oral gavage (using a stainless steel ball-tipped gavage 
needle attached to an appropriate syringe). The animals were then allowed $6 \mathrm{~h}$ before they were humanely sacrificed by cervical dislocation. The rat stomachs were carefully removed and cut through the greater curvature with a scapel blade. After rinsing with distilled water, each stomach was pinned to a white background on a wooden board and examined for ulcer lesions with the aid of a magnifying lens (x10). The ulcer index was assessed as follows: less than $1 \mathrm{~mm}=1$, between 1 and $2 \mathrm{~mm}=2$, greater than or equal to $3 \mathrm{~mm}=3$. The sum of the scores were divided by 10 (the magnification of the lens) to obtain the ulcer index for each rat [14]. The mean ulcer index for each group was compared with that of the negative control (distilled water) and the effectiveness of F8 and drug (cimetidine) was calculated using the formula: Preventive index $(\%)=$ Ulcer index of control-Ulcer index of treated/Ulcer index of control x 100. The severity of the gastric ulcer lesions in the different experimental groups was assessed.

\subsection{Purification of the bioactive fraction against gastric ulceration using TLC}

Analytical and preparative TLC techniques were employed to isolate the bioactive component in MECSL against gastric ulceration. The solvent system for the isolation of the pure sample was determined using analytical TLC. Fluorescent spots were viewed under U.V. lamp at 254 and $365 \mathrm{~nm}$ or marked and sprayed with a mixture of vanillin $(0.16 \mathrm{~g})$ in $30 \mathrm{ml}$ of concentrated tetraoxosulphate $\mathrm{IV}$ acid $\left(\mathrm{H}_{2} \mathrm{SO}_{4}\right)$. The colour reaction was recorded and the Rf value calculated based on the formula:

Rf $=\quad$ Distance traveled by the streak from the starting point

Distance traveled by the solvent from the starting point to the solvent front.

Glass plates were prepared and activated as described by Stahl [15] for preparative TLC. Streaked plates were run in a chromatographic tank containing $40 \mathrm{ml}$ Chloroform-Methanol, 2:2 as the eluting solvent for further TLC. Marked separate zones were scrapped off the glass plates with a spatula onto a clean sheet of paper. The scrapings were centrifuged in test tubes containing $5 \mathrm{ml}$ absolute methanol to separate the eluent from the adsorbent. This procedure was repeated severally for sufficient quantity of the eluent to be obtained. The pure compound, contained in the test tubes was evaporated to dryness using a hot air oven at a temperature of $40{ }^{\circ} \mathrm{C}$. In vivo bioassay evaluation of the bioactive compound using indomethacin-induced gastric ulcer model was performed in rats as previously described in 2.6 to confirm the antiulcer activity. The pure fraction was then weighed, sealed and labeled for structural and molecular elucidation.

\subsection{Identification of the active principle against gastric ulceration in MECSL}

The study was conducted at the Chemistry Laboratory of Bielefeld University, Germany. Onedimensional experiments: Nuclear Magnetic Resonance (NMR) spectroscopy and mass spectrometry (MS) were used extensively to detect the simple compounds in the sample (PF8). Most of the NMR data were obtained on a JEOL Eclipse (400 MHZ) but some were determined using a Bruker (600 MHZ) where better dispersion was required. Deuterated methanol was used in the initial step to check purity of the sample and to identify the type of sample. ${ }^{1} \mathrm{H}$ NMR is one dimensional experiment presenting information about the nature of protons in the molecule, the number, chemical shifts, multiplicity, coupling constant and intensity. Carbon 13 NMR $\left({ }^{13} \mathrm{CNMR}\right)$ was used to obtain information on the number of carbon atoms in the molecule. Mass spectrometry was used for determination of the molecular mass.

\subsection{Statistical analysis}

The mean ulcer index for each experimental group, expressed as mean \pm SEM (Standard error of the mean) was subjected to Mann-Whitney test and differences at $p<0.05$ or $p<0.01$ were considered significant.

\subsection{Extraction of the plant material}

\section{Results}

The MECSL was dark brown in colour with a pleasant smell. The extraction process gave a yield of 11.8 percent $(w / w)$.

\subsection{Column chromatography}

Fractionation of the crude MECSL yielded eight component fractions with varying colorations at $254 \mathrm{~nm}$ but quenched at $356 \mathrm{~nm}$. Fraction 1 (F1) was grey with Rf 0.67; F2: yellowish brown, Rf 0.40; F3: pink, Rf 0.51; F4: light yellow, Rf 0.41; F5: brown, Rf 0.27; F6: orange, Rf 0.62; F7: reddish brown, Rf 0.43 and F8: dark brown, $\mathrm{Rf} 0.82$. Rf referred to the relative retention factor. 


\subsection{Bioassay screening of the bioactive fraction with indomethacin-induced gastric ulceration}

Fraction (F8) was selected as the bioactive component in the MECSL. The fraction produced a complete $(100 \%)$ gastroprotective effect at $100 \mu \mathrm{g} / \mathrm{kg}$ against indomethacin-induced ulcerative lesions in rats. The $100 \%$ protective effect of the bioactive fraction (F8) was highly significant ( $\mathrm{p}<0.01)$ and remarkable compared to $73 \%$ preventive index with cimetidine $(100 \mathrm{mg} / \mathrm{kg})$, the reference antiulcer drug (Table 1). There was no trace of ulcer lesion in the stomach of any of the five rats treated with F8 in contrast to the rest of the animals that received distilled water or cimetidine.

Table 1

In vivo gastroprotective effects of the bioactive fraction (F8) of Cassia singueaena extract against indomethacininduced gastric ulceration in rats

Group/Treatment No. of animal Mean ulcer index \pm s.e. $\quad$ Preventive index (\%)

\begin{tabular}{|c|c|c|c|}
\hline $\begin{array}{l}\text { I: Negative control } \\
\text { (D.w., } 10 \mathrm{ml} / \mathrm{kg} \text { ) }\end{array}$ & 5 & $1.53 \pm 0.15$ & 0 \\
\hline II: Cimetidine (100 mg/kg) & 5 & $0.42 \pm 0.14^{\mathrm{a}}$ & 73 \\
\hline 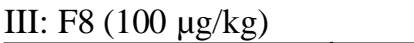 & 5 & 0.00 & 100 \\
\hline
\end{tabular}

$\mathrm{F} 8=$ fraction 8.

\subsection{Purification of the bioactive fraction (F8) in Cassia singueana leaf extract using TLC}

Chloroform-methanol (2:2) was the best solvent system for the resolution of the bioactive fraction (F8). Further fractionation and purification of the bioactive fraction against gastric ulceration in MECSL afforded the isolation of $22 \mathrm{mg}$, a 0.44 percent yield of the pure antiulcer principle (PF8). PF8 had Rf value of 0.82 and yellowish in colour.

\subsection{Identification of the active principle from MECSL against gastric ulceration}

The structural and molecular elucidation using NMR and mass spectrometry facilitated the identification of the bioactive principle (PF8) against gastric ulceration in $C$. singueana leaves as luteolin. Luteolin had a melting point of $328-330^{\circ} \mathrm{C}$, molecular weight of $286.24 \mathrm{~g}$ and yellowish in colour. The molecular formula was deduced as $\mathrm{C}_{15} \mathrm{H}_{10} \mathrm{O}_{6}$. The detailed bond connectivity and assignments of all the ${ }^{1} \mathrm{H}$ and ${ }^{13} \mathrm{C}$ NMR signals were obtained from the HMQC, COSY and HMBC data (Figures 1-4).

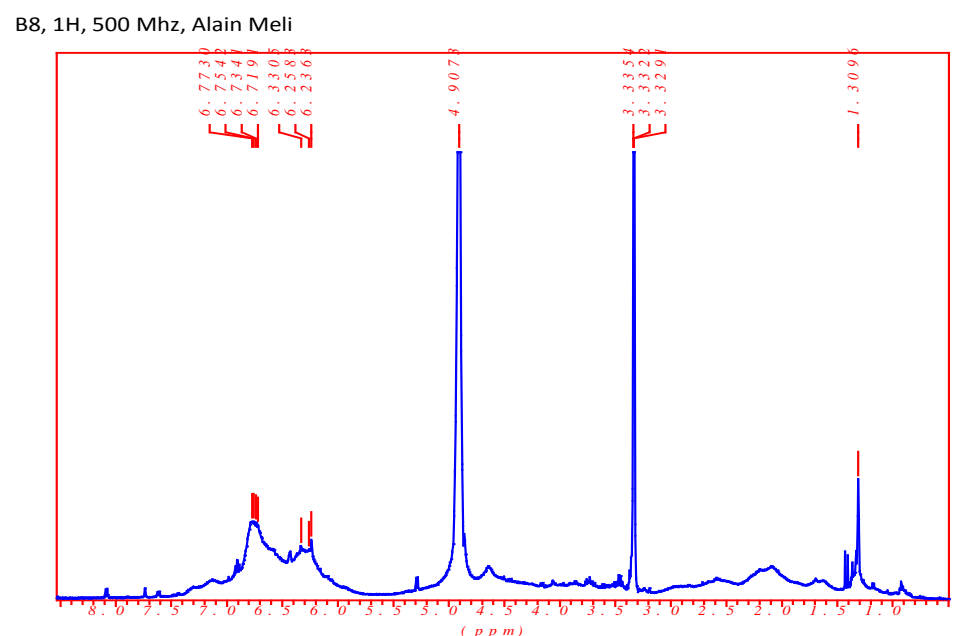

Figure 1: ${ }^{13} \mathrm{C}-\mathrm{NMR}$ spectrum of luteolin isolated from Cassia singueana leaf extract 


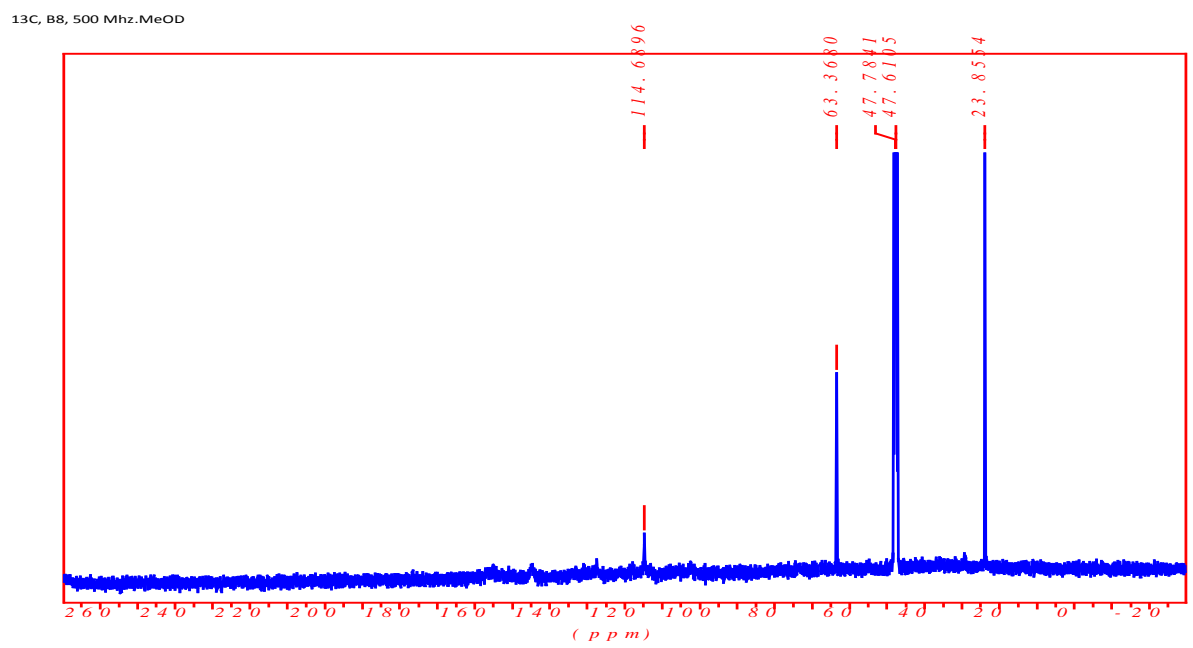

Figure 2: Further spectrum of luteolin isolated from Cassia singueana leaf extract

\section{ChemNMR C-13}

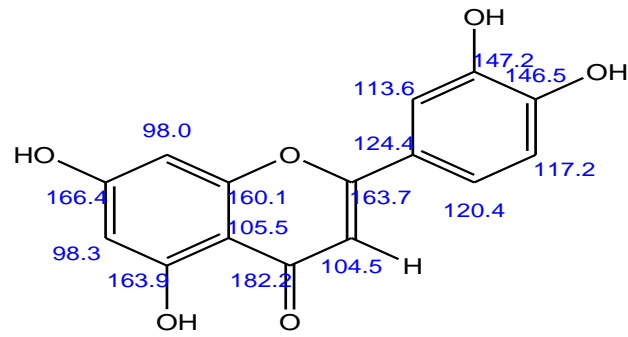

Figure 3: NMR spectrum of luteolin isolated from Cassia singueana leaf extract showing ${ }^{13} \mathrm{C}-\mathrm{NMR}$ peaks

\section{ChemNMR H-1}

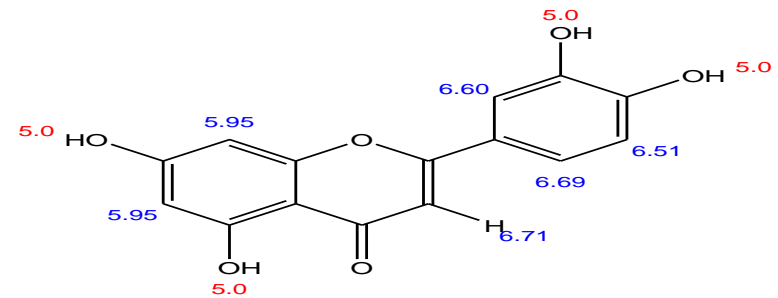

Figure 4: NMR spectrum of luteolin isolated from Cassia singueana leaf extract showing ${ }^{1} \mathrm{H}-\mathrm{NMR}$ peaks

The bond connectivity of the isolate (luteolin) is further presented below:
$(1 \mathrm{H}, \mathrm{s}, \mathrm{H}-1)$
$1 \mathrm{H}, \mathrm{s}, \mathrm{H}-3$

$\left.{ }^{1} \mathrm{H}-\mathrm{NMR}\left(400 \mathrm{MH}_{3}\right): 5.95(1 \mathrm{H}, \mathrm{s}, \mathrm{H})_{1}\right), 5.90(1 \mathrm{H}, \mathrm{sH}-3), 5.00(1 \mathrm{H},-\mathrm{OH})$

$6.71(1 \mathrm{H}, \mathrm{s}, \mathrm{H}-6), 6.69(1 \mathrm{H}, \mathrm{s}, \mathrm{H}-2)$

$$
6.51\left(1 \mathrm{H}, \mathrm{s}, \mathrm{H}-3^{1}\right), 6.60\left(1 \mathrm{H}, \mathrm{s}, \mathrm{H}-6^{1}\right)
$$

${ }^{13} \mathrm{C}-\mathrm{NMR}\left(100 \mathrm{MH}_{3}\right) \quad 98.0$ (C-1), 166.4 (C-2), 98.3 (C-3)

163.9 (C-4), 105.5 (C-4a), 182.2 (C-5)

104.5 (C-6), 163.7 (C-7), 160.1 (C-7a),

$124.4\left(\mathrm{C}-2^{1}\right), 117.2\left(\mathrm{C}-3^{1}\right)$

$146.5(\mathrm{C}-4), 147.2\left(\mathrm{C}-5^{1}\right), 113.6\left(\mathrm{C}-6^{1}\right)$ 


\section{DISCUSSION}

Earlier investigations established that the crude methanol extract of $C$. singueana leaves inhibited histamine-induced stomach ulcers in rats [7], an indication of the presence of pharmacologically active compounds with histamine- $\mathrm{H}_{2}$ receptor antagonists or proton pump inhibitors. Histamine is crucial for the production of gastric hydrochloric acid and ulcerogenesis in the gastro-intestinal tract. The inhibition of indomethacin-mediated stomach ulcer lesions in rats [8] is supported by the results of the present in vivo bioassay test when pure fraction (PF8) offered a complete (100\%) protective effect against indomethacininduced ulcerogenic tendencies in 5 rats (Table 1). The active principle exhibited anti-inflammatory potency with selective inhibition of cyclooxygenase II-dependent prostaglandin biosynthesis. Cyclooxygenase I is a constitutive enzyme, the secretions are valuable for tissue homeostasis and its inhibition gives rise to gastric ulceration [16]. Cyclooxygenase II (COX-2) expression on the other hand, is triggered off by inflammatory process; hence selective inhibition of COX-2 represents a selective blockade of prostaglandin biosynthesis during inflammation [17]. The effects of PF8 were not observed to have aggravated ulcer lesions caused by indomethacin treatment, hence cyclooxygenase I enzymes were not likely affected. The crude extract was also reported to have suppressed stomach ulcer lesions induced with ethanol in experimental rats [9] suggesting that the extract had potent components that reduced oxidative-mediated tissue damage. This was equally exemplified in the high antioxidant capacity of the leaf extract [10]. Ethanol disrupts gastric mucosal barriers through generation of reactive oxygen species [18]. Bioassay-guided fractionation of the crude extract facilitated the isolation of the bioactive fraction (F8) against gastric ulcer and the antiulcer principle, identified as luteolin on structural and molecular elucidation. This marked the first report of isolation of luteolin from C. singuena leaves and its association with antiulcer activities.

Luteolin is considered to be non-toxic; the $\mathrm{LD}_{50}$ per os in rat is reportedly greater than $5000 \mathrm{mg} / \mathrm{kg}$ but $2500 \mathrm{mg} / \mathrm{kg}$ in mouse $[19,20]$. The compound displays anti-inflammatory and antinociceptive activities $[21,22,23]$. Luteolin has anticarcinogenic, antimutagenic and antiangiogenic properties. It shows strong antiproliferative activity against different human cancer cell lines as in solid malignancies and hormone dependent cancer lines e.g. breast, prostate, and thyroid cancer $[24,25,26]$. Luteolin is a selective inhibitor of COX II; the anti-inflammatory effects are not therefore, associated with gastric ulceration which is common with the use of non-steroidal anti-inflamatory drugs. The inhibition of COX II activities blocks prostaglandininduced elaboration of prostanoid mediators of inflammation and hyperalgesia experienced by ulcer patients [17].

Luteolin also has high antioxidant potential, measured in Trolox test, is twice stronger than vitamin $\mathrm{E}$ [27]. Consequently, the compound would be valuable in the management of diverse diseases including peptic ulcers in which reactive oxygen species are known to contribute to the pathologies. Luteolin can be used in place of cimetidine because it is known to possess high anti-histaminic properties [28] and this would reduce excessive secretion of hydrochloric acid into the gastric lumen to initiate or aggravate ulceration. The vasodilatory effects of the compound would enhance submucosal blood flow to facilitate rapid ulcer healing. The mechanism of vasodilatory action of luteolin apparently involves inhibition of protein kinase $\mathrm{C}$ and possibly the inhibition of cyclic nucleotide phosphodiesterase [29]. Again, luteolin has bacteriostatic properties and it acts as an uncompetitive (selective) inhibitor of arylamine $\mathrm{N}$-acetyltransferase in $\mathrm{H}$. pylori [30], the pathogens responsible for development of gastro-intestinal ulcers.

\section{CONCLUSION}

Luteolin isolate from the extract of $C$. singueana leaves was identified as the antiulcer agent with broad mechanism of actions. The compound is known to be safe, possesses anti-terratogenic, anti-mutagenic, antihistaminic, high antioxidant, antinociceptive and vasodilatory activities. Luteolin was also reported to have antiinflammatory and bacteriostatic effects with inhibition of cyclooxygenase II and a selective inhibition of $H$. pylori, the dominant bacteria associated with gastritis. These effects are all inclusive and indispensable to the healing of peptic ulcers. Luteolin could therefore take the place of a sole antiulcer agent based on the broad mechanisms of action.

\section{FUNDING SOURCES}

The research was strictly conducted out of personal savings of the authors and no involvement of external sponsors.

\section{Acknowledgements}

The authors wish to sincerely thank Mr. A.O. Ozioko of BDCP, Nsukka, Enugu State, Nigeria for identifying the plant sample and the staff of Chemistry Laboratory in Bielefeld University, Germany for their contributions in the molecular elucidation of the bioactive principle. 


\section{REFERENCES}

[1] K. Takeuchi, and S. Okabe, Acid back-diffusion and mucosal $\mathrm{H}^{+}$handling in the rat stomach under normal and stress-induced conditions, The Japanese J. Pharmacol., 33, 1982, 85-93.

[2] H. Tanaka, K. Shuto, and N. Nakamizo, Exacerbation of acetic acid induced by Non-steroidal anti-inflammatory drugs in rats, The Japanese J. Pharmacol., 33, 1983, 447-454.

[3] T. Brzozowski, P.C.H. Konturek, Z. Sliwowski, D. Drozdowicz, E.G. Hahn, and S.J. Konturek, Importance of nitric oxide and capsaicin-sensitive afferent nerves in healing of stress lesions induced by epidermal growth factor, J. Clin. Gastroenterol., 25, 1997, 28-38.

[4] D.R. Laurence, P.N. Bennett, and M.J. Brown, Clinical Pharmacology (London: Churchill Livingstone, 1997) 567-578.

[5] P.L. Munson, R.A. Mueller, and G. R. Breese, Principles of pharmacology: Basic concepts and clinical applications (USA: Chapman \& Hall, 1995) 1063-1081

[6] J. Blum, A. Garner, and I. Fridovich, Inactivation of glutathione peroxidase by superoxide radical, Arch. Biophys., 240, 1986, 500 .

[7] O.J. Ode, G.M. Oladele, and O.V. Asuzu, The protective effects of the methanolic extract of Cassia singueana leaves against histamine-induced stomach ulcers in albino rats, International Journal of Plant Animal and Environmental Sciences, 1, 2011, 5460 .

[8] O.J. Ode, The antiulcer activities of the methanol extract of Cassia singueana leaves using indomethacin-induced gastric ulcer model in rats, Journal of Advanced Scientific Research, 2, 2011, 66-69.

[9] O. J. Ode, and O.V. Asuzu, Investigation of Cassia singueana leaf extract for antiulcer effects using ethanol-induced gastric ulcer model in rats, International Journal of Plant Animal and Environmental Sciences, 1, 2011, 1-7.

[10] I.I. Madubunyi, and O.J. Ode, In vitro and in vivo antioxidant potential of the methanolic extract of Cassia singueana Delile (Fabaceae) Lock leaves), Comparative Clinical Pathology, 2011, DOI: 10.1007/s00580-011-1328-y.

[11] EU Council Directive of 24 November on the approximation of laws, regulations and administrative provisions of the member states regarding the protection of animals used for experimental and other scientific purposes (86/609/EEC), 1986.

[12] Directive 2010/63/EU of the European Parliament and of the Council of 22 September on the protection of animals used for scientific purposes, 2010.

[13] D. Abbot, and R.S. Andrews, An Introduction to chromatography, 2 (London: Longman press, 1970) $72-78$

[14] I.H.M. Main, and B.R. Whittle, The effect of E and A prostaglandin on gastric mucosal blood flow and acid secretion in Rats, Br. J. Pharmacol., 53, 1975, 217-224.

[15] E. Stahl, Thin layer chromatography: A handbook (New York: Springerverlag, Berlin-Herdberg, 1969) 60-204.

[16] D. B. McNamara, and P.R. Mayeux, Nonopiate analgesics and anti-inflammatory drugs. In: P.L. Munson, R.A. Mueller, and G.R. Breese (Eds.), Principles of Pharmacology: Basic concepts and clinical applications (USA: Chapman \& Hall, 1995 ) 1162.

[17] H.P. Rang, M.M. Dale, J.M. Ritter, and P.K. Moore, Pharmacology (London: Churchill Livingstone, 2003) 223, $572-584$.

[18] P.C.H. Konturek, A. Duda, and T. Brzozowski, Activation of genes for superoxide dismutase, interleukin-1ß), tumour necrosis factor- $\alpha$ ) and intercellular adhesion molecule-1 during healing of ischaemia-reperfusion gastric injury, Scand. J. Gastroenterol., $35,2000,452-463$.

[19] L.M. Dai, H. Cheng, W.P. Li, S.Q. Liu, M.Z. Chen, and S.Y. Xu, Determination of the acute toxicity of luteolin in rats, Acta Anhui Med. Univ., 20, 1985, 1-3.

[20] B. Fiszer-Szafaraz, The oral $\mathrm{LD}_{50}$ of luteolin in mice, Analyt. Biochem., 143, 1984,76-84.

[21] T. Karrasch, K.J. Kim, B.I. Jang, and C. Jobin, The flavonoid luteolin worsens chemical-induced colitis in NF-KB EGFP Transgenic mice through blockade of NF-KB-Dependent protective molecules, PLoS ONE 2, 2007, e596.

[22] J.J. Hendriks, J. Alblas, S.M. Vander Pol, E.A.Van Tol, and C.D. Dijkstra, Flavonoids influence monocytic GTpase activity and are protective in experimental allergic encephalitis, J. Exp. Med., 2004,1667-1672.

[23] L.C. Block, A.R. Santos, M.M. de souza, C. Scheidt, M.A.Santos, F.D. Monache, and V. Filho, Antinociceptive effect of luteolin, J. Ethnopharmacol., 61, 1998, 85-89.

[24] J.F.M. Post, and R.S. Varma, Luteolin, a growth inhibitor in cancer cells, Cancer Lett., 67, 1992, $207-213$.

[25] R. Ramanthan, N.P. Das, and C.H. Tan, In vitro effects of natural plant polyphenols on tumuor and cell proliferation, Int. J. Oncol., 3, 1993, 115-119.

[26] S. Y. Ryu, S.U. Choi, C.O. Lee, S.H. Lee, J.W. Ahn, and O.P. Zee, Anti-proliferative activity of luteolin against cancer, Arch. Pharm. Res., 17, 1994, 42-44.

[27] N.J. Miller, Natural Antioxidants and Food Quality in Atherosclerosis and Cancer Prevention. In: J.T. Kumpulainen, and J.T. Salonen (Eds.), The Royal Society of Chemistry, 1996, 256-259.

[28] M. Amellal, C. Bronner, F. Briancon, M. Haag, R. Anton, and Y. Landry, Luteolin displays anti-histamine properties. Planta Med., 1, 1994, 16-20.

[29] E.C. Chan, P. Pannangpetch, and O.L. Woodman, The mechanism of vasodilatory action of luteolin. Cardiovasc. Pharmacol., 35, 2000, 326-333.

[30] G. Ciaceri, and G. Attagguile, Luteolin inhibits Helicobacter pylori, Minerva Med., 63, 1972, $1665-1668$. 